\title{
Isojacareubin from the Chinese Herb Hypericum japonicum: Potent Antibacterial and Synergistic Effects on Clinical Methicillin-Resistant Staphylococcus aureus (MRSA)
}

Guo-Ying Zuo ${ }^{1}$, Jing An ${ }^{1,2}$, Jun Han ${ }^{3}$, Yun-Ling Zhang ${ }^{1}$, Gen-Chun Wang ${ }^{1}$, Xiao-Yan Hao ${ }^{2}$ and Zhong-Qi Bian ${ }^{4} *$

1 Research Center for Natural Medicines, Kunming General Hospital, PLA, Kunming 650032, China; E-Mails: zuoguoying@263.net (G.-Y.Z.); anjingmail@163.com (J.A.); zhangyunling@126.com (Y.-L.Z.); kmwgc12@126.com (G.-C.W.)

2 School of Pharmacy, Guiyang Medical University, Guiyang 550004, Guizhou, China; E-Mail: haoxiaoyan@vip.163.com

3 School of Basic Medical Sciences, Yunnan Traditional Chinese Medical College, Kunming 650500, China; E-Mail: hanzjn@126.com

4 Center for Infectious Diseases, Kunming General Hospital, PLA, Kunming 650032, China

* Author to whom correspondence should be addressed; E-Mail: bzq@ynu.edu.cn; Tel./Fax: +86-871-477-4941.

Received: 7 May 2012; in revised form: 31 May 2012 / Accepted: 18 June 2012 / Published: 3 July 2012

Abstract: Through bioassay-guided fractionation of the extracts from the aerial parts of the Chinese herb Hypericum japonicum Thunb. Murray, Isojacareubin (ISJ) was characterized as a potent antibacterial compound against the clinical methicillin-resistant Staphylococcus aureus (MRSA). The broth microdilution assay was used to determine the minimal inhibitory concentrations (MICs) and minimal bactericidal concentrations (MBCs) of ISJ alone. The results showed that its MICs/MBCs ranged from 4/16 to $16 / 64 \mu \mathrm{g} / \mathrm{mL}$, with the concentrations required to inhibit or kill $50 \%$ of the strains $\left(\mathrm{MIC}_{50} / \mathrm{MBC}_{50}\right)$ at $8 / 16 \mu \mathrm{g} / \mathrm{mL}$. Synergistic evaluations of this compound with four conventional antibacterial agents representing different types were performed by the chequerboard and time-kill tests. The chequerboard method showed significant synergy effects when ISJ was combined with Ceftazidime (CAZ), Levofloxacin (LEV) and Ampicillin (AMP), with the values of 50\% of the fractional inhibitory concentration indices $\left(\mathrm{FICI}_{50}\right)$ at $0.25,0.37$ and 0.37 , respectively. Combined bactericidal activities were also observed in the time-kill dynamic assay. The 
results showed the ability of ISJ to reduce MRSA viable counts by $\log _{10} \mathrm{CFU} / \mathrm{mL}$ at $24 \mathrm{~h}$ of incubation at a concentration of $1 \times$ MIC were 1.5 (LEV, additivity), 0.92 (CAZ, indifference) and 0.82 (AMP, indifference), respectively. These in vitro anti-MRSA activities of ISJ alone and its synergy with conventional antibacterial agents demonstrated that ISJ enhanced their efficacy, which is of potential use for single and combinatory therapy of patients infected with MRSA.

Keywords: anti-MRSA activity; Hypericum japonicum; Isojacareubin; MIC; synergy

\section{Introduction}

Presently, the global spread of methicillin-resistant Staphylococcus aureus (MRSA) is of great concern in the treatment of Staphylococcal infections, since it has quickly acquired resistance to all clinical antibacterial agents. Even a glycopeptides resistant strain, i.e., Vancomycin resistant S. aureus (VRSA) has also been reported [1]. MRSA has become the most common cause of infections among many pathogenic bacteria, leading to many life-threatening diseases such as endocarditis, pneumonia and toxin shock syndrome. In our hospital, MRSA could be found in over 80 percent of sputum samples of pneumonia elderly patients in the intensive care unit (ICU). Therefore, the developing of agents with novel modes of action is vital for overcoming this troublesome pathogen. Synergy of photochemicals with antibiotics has been viewed as approaching a new generation of phytopharmaceuticals $[2,3]$. We are devoting effort to search for novel anti-MRSA agents from plant sources with use in traditional Chinese medicine (TCM) in recent years [4-8].

Hypericum japonicum Thunb. ex Murray (Di-er-cao or Tian-ji-huang in Chinese; Guttiferae) was first recorded in Zhiwu Mingshi Tukao (or Illustrated Catalogue of Plants) which dates back to 1848 [9,10]. This medicinal plant has been used to treat viral hepatitis and other infectious diseases for over one hundred years. Bioassay-guided fractionation of the alcoholic extract of the aerial parts of Hypericum japonicum led us to identify an anti-MRSA xanthone Isojacareubin (ISJ). The present report investigates the anti-MRSA activity of this compound alone and its synergistic effects in combination with conventional antibacterial agents.

\section{Results and Discussion}

ISJ was isolated through bioassay-guided fractionation of extracts from $H$. japonicum (Table 1) [4]. Its structure was elucidated and identified mainly by spectral analysis and compared with a previous report (Scheme 1) [11]. Ten MRSA isolates, which were used for the evaluation of antibacterial activities, were characterized [4-8], and the presence of the mecA gene and SCCmec genotypes (Figure 1) was demonstrated through multiplex PCR experiments [12].

The in vitro anti-MRSA activities of ISJ and four conventional antibacterial agents, i.e., Ampicillin (AMP), Ceftazidime (CAZ), Levofloxacin (LEV) and Azithromycin (AZM) both alone and combined, against the 10 clinical MRSA strains of SCCmec III type [12] are shown in Table 2. The ranges of minimal inhibitory concentrations/minimal bactericidal concentrations (MICs/MBCs, $\mu \mathrm{g} / \mathrm{mL}$ ) alone 
were 4 16/16 64 for ISJ, within the order of potency as ISJ (4 16/16 64) = LEV (4 16/8 64) $>$ AMP $(16 \sim 128 / 64 \sim 512)>$ CAZ $(128 \sim 512 / 128 \sim>1024)>>$ AZM $(>1024)$, so the potency of ISJ and LEV were nearly equivalent. In the control experiments, MICs and MBCs of Vancomycin and ISJ against the methicillin-susceptible $S$. aureus (MSSA, ATCC 25923) strain were $1 / 2$ and $8 / 16 \mu \mathrm{g} / \mathrm{mL}$, respectively.

Table 1. The screening results of different extraction parts (diameter of inhibition zone: $\mathrm{mm})^{a}$.

\begin{tabular}{lcc}
\hline Strains $^{a}$ & MSSA (ATCC25923) & MRSA 004 \\
\hline Petroleum ether part & 29 & 23 \\
Ethyl acetate part & 22 & 23 \\
Sub-ethyl acetate fraction-A (Fr. A) & 17 & 23 \\
Sub-ethyl acetate fraction-B (Fr. B) & 20 & 15 \\
Sub-ethyl acetate fraction-C (Fr. C 2$)$ & 30 & 29 \\
$n$-Butanol part & 15 & 17 \\
Water part & 15 & 12 \\
Vancomycin & 30 & 30 \\
\hline
\end{tabular}

${ }^{a}$ Determined at a concentration of $30.0 \mathrm{mg} / \mathrm{mL}$ for the extracts and $1.0 \mathrm{mg} / \mathrm{mL}$ for Vancomycin; ${ }^{b}$ MSSA: methicillin-susceptible Staphylococcus aureus; MRSA 004: A strain of methicillinresistant S. aureus.

Scheme 1. The structure of Isojacareubin (ISJ).<smiles>CC1(C)CC[C@@H]2OC3=C(O[C@H]2C1)c1c(O)cc(O)cc1C3=O</smiles>

Figure 1. SCCmec III genotyping of methicillin-resistant Staphylococcus aureus (MRSA) genes (M: marker, 1: mecA, 2: CCRA1, 3: CCRA2, 4: CCRA3, 5: mec I, 6:IS1272).

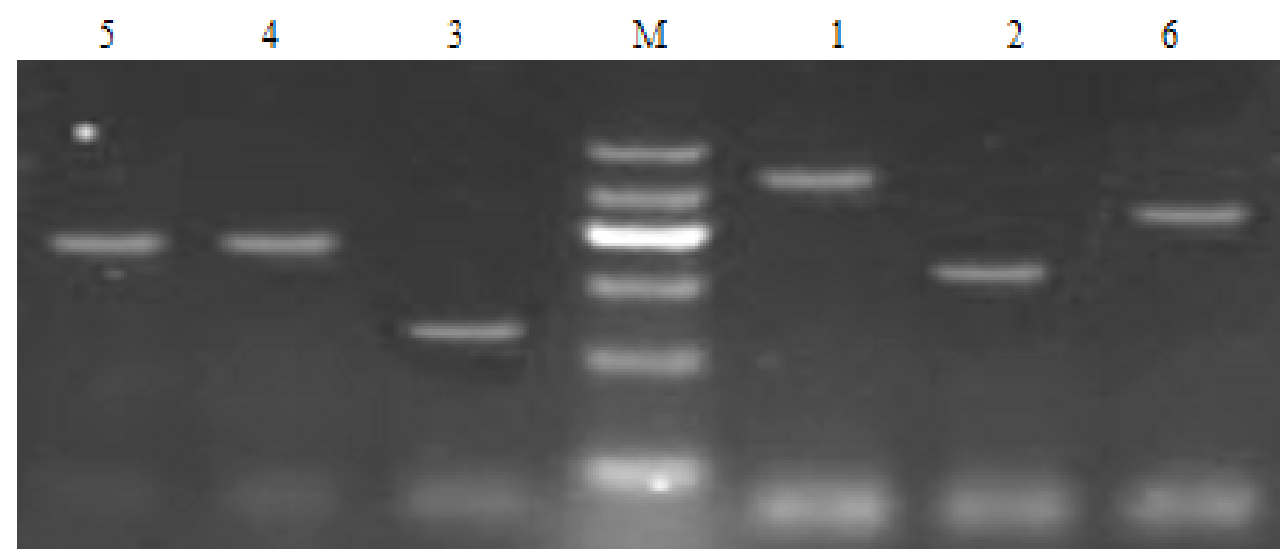


Table 2. MICs (/MBCs; $\mu \mathrm{g} / \mathrm{mL})$ and fractional inhibitory concentration indices (FICIs) of Isojacareubin in combination with four conventional antibacterial agents against 10 clinical isolates of SCCmec III type MRSA.

\begin{tabular}{|c|c|c|c|c|c|c|c|c|c|}
\hline \multirow{2}{*}{ Agents } & \multirow{2}{*}{$\frac{\text { ISJ }^{a}}{\text { Alone }}$} & \multicolumn{2}{|c|}{ AMP } & \multicolumn{2}{|c|}{ CAZ } & \multicolumn{2}{|c|}{ LEV } & \multicolumn{2}{|c|}{ AZM } \\
\hline & & Alone & $\mathrm{Comb}^{b}$ & Alone & Comb & Alone & Comb & Alone & Comb \\
\hline Ranges of & $4(/ 16) \sim$ & $16(/ 64) \sim$ & $4 \sim 16+1 \sim 4$ & $128(/ 128) \sim$ & $32 \sim 128+$ & $4(/ 8) \sim$ & $1 \sim 4+$ & ex & $512 \sim 1024$ \\
\hline MIC (/MBC) & $16(/ 64)$ & $128(/ 512)$ & & $512(/ \mathrm{ex})+$ & $1 \sim 4$ & $16(/ 64)$ & $1 \sim 4$ & & $+4 \sim 16$ \\
\hline$(\mu \mathrm{g} / \mathrm{mL})^{c}$ & & & & $32 \sim 128$ & & & & & \\
\hline $\mathrm{MIC}_{50}{ }^{c}$ & 8 & 64 & $8+4$ & 512 & $32+1$ & 16 & $2+2$ & - & $1024+8$ \\
\hline $\mathrm{MIC}_{90}$ & 16 & 128 & $16+4$ & 512 & $64+4$ & 16 & $4+4$ & - & $1024+16$ \\
\hline Ranges of & - & - & $0.37 \sim 0.62$ & - & $0.25 \sim 0.5$ & - & $0.25 \sim 0.5$ & - & $1 \sim 1.5$ \\
\hline FICI $^{d}$ & & & & & & & & & \\
\hline $\mathrm{FICI}_{50}$ & - & - & 0.37 & - & 0.25 & - & 0.37 & - & 1.5 \\
\hline $\mathrm{FICI}_{90}$ & - & - & 0.62 & - & 0.37 & - & 0.37 & - & 1.5 \\
\hline Effect $(\%)^{e}$ & - & - & $\operatorname{ad}(30) \operatorname{sn}(70)$ & - & $\operatorname{sn}(100)$ & - & $\operatorname{sn}(100)$ & - & $\mathrm{id}(100)$ \\
\hline
\end{tabular}

${ }^{a}$ ISJ, Isojacareubin; AMP, Ampicillin; CAZ, Ceftazidime; LEV, Levofloxacin; AZM, Azithromycin; ${ }^{b}$ Comb, combined (the binate data are expressed as values of single antibacterial $+\mathrm{ISJ}$ ); ${ }^{c} \mathrm{MIC}_{50}$, concentration of inhibition against $50 \%$ of MRSA strains; $\mathrm{MIC}_{90}$, concentration of inhibition against $90 \%$ of MRSA strains; ex, concentration of $>1024 \mu \mathrm{g} / \mathrm{mL}$; ${ }^{d} \mathrm{FICI}_{50}$, FICI of inhibition against $50 \%$ MRSA strains; $\mathrm{FICI}_{90}$, FICI of inhibition against $90 \%$ MRSA strains; ${ }^{e}$ ad, additivity; id, indifference; sn, synergy.

Tested by the chequerboard method [13], ISJ showed synergy when it was combined with various antibacterials, with the values of $50 \%$ of the fractional inhibitory concentration indices $\left(\mathrm{FICI}_{50}\right)$ at 0.37 (AMP), 0.25 (CAZ) and 0.37 (LEV), respectively. However, the ISJ and AZM combination showed indifference $\left(\mathrm{FICI}_{50}=1.50\right)$. The combination of ISJ with CAZ was observed as the most effective, with their values of $\mathrm{MIC}_{50}(\mu \mathrm{g} / \mathrm{mL})$ reduced from 8 (ISJ alone) and 512 (CAZ alone) to $1+32$ $(\mathrm{ISJ}+\mathrm{CAZ})$. Combination of ISJ and LEV was observed as less effective, with their values of $\mathrm{MIC}_{50}$ $(\mu \mathrm{g} / \mathrm{mL})$ reduced from 8 (ISJ alone) and 16 (LEV alone) to both 2 (ISJ + LEV). According to the CLSI interpretive standard for Staphylococcus spp., these values were close to the MICs $(\mu \mathrm{g} / \mathrm{mL})$ of breakpoints of LEV ( $\leq 1$ for susceptible and $\geq 4$ for resistant) and CAZ ( $\leq 8$ for susceptible and $\geq 32$ for resistant), respectively, which demonstrated significant potentiation of anti-MRSA effects (or even reversion of the resistance of the corresponding antibacterial agents against MRSA) [14].

Time-kill curves (Figure 2) showed ISJ alone was the most effective at reducing the viable counts by $4.66 \log _{10} \mathrm{CFU} / \mathrm{mL}(-4.66$, synergy) of MRSA at $24 \mathrm{~h}$ of incubation at the concentration of $1 \times \mathrm{MIC}$, while the counts $\left(\log _{10} \mathrm{CFU} / \mathrm{mL}\right)$ of combinations of ISJ with AMP $(-0.82$, indifference), CAZ ( -0.92 , indifference), LEV ( -1.5 , additivity) and AZM $(+0.53$, indifference) were also observed against MR004 (one of the ten isolates) (data not shown). Therefore, the combined bactericidal activities were not as potent as those of bacteriostatic at the concentration of $1 \times$ MIC [15]. Concentrations of higher MIC times of ISJ might produce better combinatory bactericidal effects. 
Figure 2. Time-kill curves of the synergistic effect of the combination of Isojacareubin (ISJ) at $1 \times$ MIC concentration with Ampicillin (AMP) (A); Ceftazidime (CAZ) (B); Levofloxacin (LEV) (C); and Azithromycin (AZM) (D); against MR004, a clinical MRSA strain of SCCmec III type.
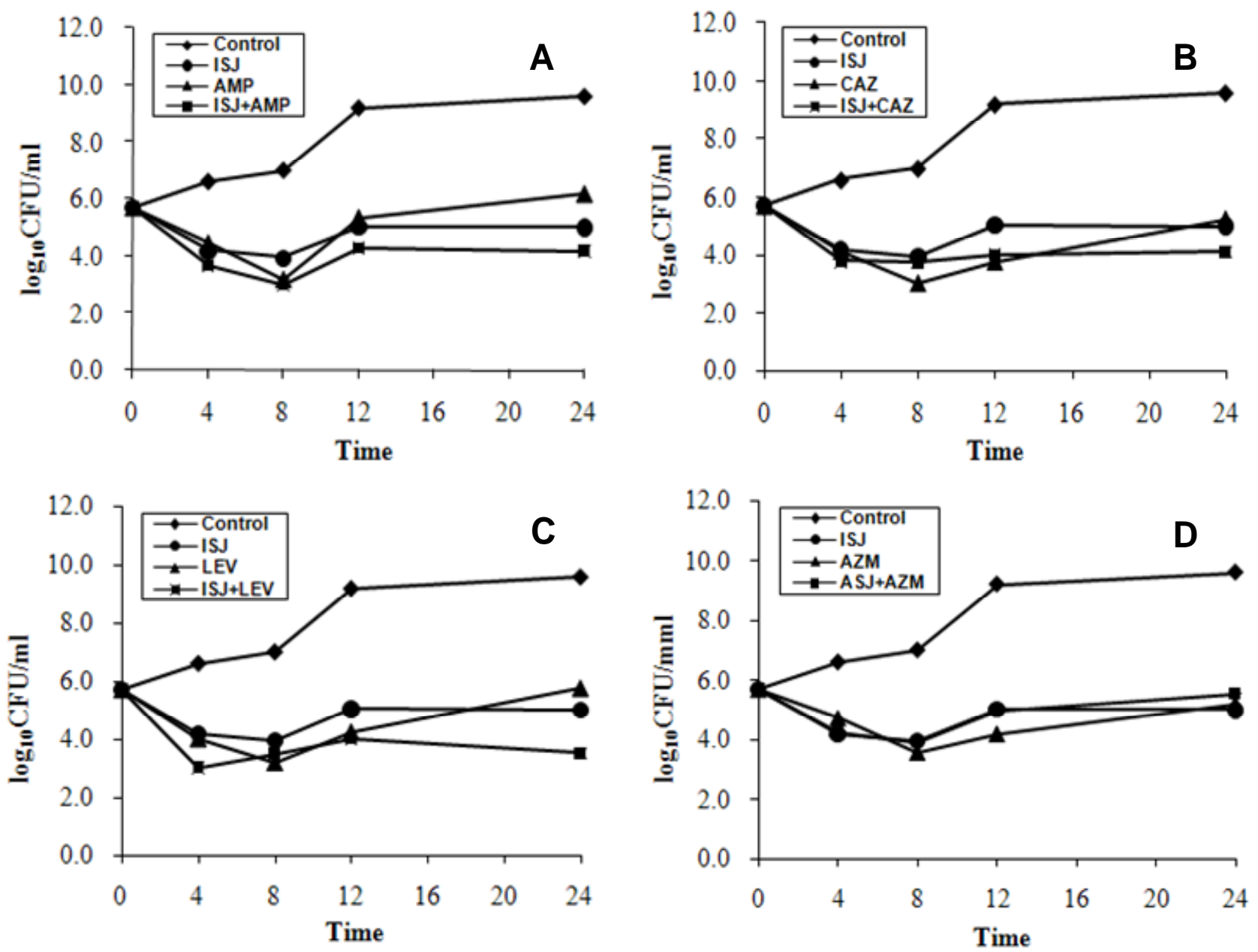

$H$. japonicum is a Chinese herb used in TCM. Its $85 \%$ ethanol treated water extract was documented in Chinese Pharmacopoeia as an injection for the treatment of viral hepatitis [16]. In Europe, a plant of the same genus, i.e., H. perforatum is known by the name St John's wort, which is a first-line herbal medicine used for mild to moderate depression [17]. These records demonstrated their safety of therapeutic properties. ISJ is a characteristic constituent in $H$. japonicum and was first found in the plant by Ishiguro et al. [11]. Although many xanthone derivatives have been studied for their antimicrobial (including anti-MRSA) activities, the limited distribution in plant resources has meant that ISJ remained as yet to be investigated to the best of our knowledge [18-20]. For the first time we studied its anti-MRSA activities in this report.

As the clinical MRSA which was originally called the "superbug" has been haunting us in recent years and has become an increasingly pressing clinical problem worldwide, anti-MRSA synergistic effects between plant natural compounds and conventional antibacterial agents has further been demonstrated here as a promising way of overcoming current antibiotic resistances [3]. 


\section{Experimental Section}

\subsection{Plant Materials}

The aerial parts of $H$. japonicum were purchased from the crude drug mart in Kunming, China. They were identified at the Botany Department, Kunming Institute of Botany (KIB), the Chinese Academy of Sciences. The voucher specimen is deposited at the herbarium of KIB.

\subsection{Bacterial Strains and Media}

MRSA strains (ten isolates with SCCmec III genotype) were obtained and characterized from the infectious sputum samples of critically ill patients in Kunming General Hospital [14,21,22]. The presence of mecA gene and SCCmec genotypes were determined by multiplex PCR method (Figure 1) [12]. ATCC 25923 was used as the control strain. Standard Mueller-Hinton agar and broth (MHA and MHB, Tianhe Microbial Agents Co., Hangzhou, China) were used as bacterial culture media. MHB was used for all susceptibility testing and time-kill experiments. Colony counts were determined using MHA plates.

\subsection{Antibacterial Agents}

Four antibacterial agents representing four conventional agents used in clinic were purchased from the manufacturers, i.e., Ampicillin (AMP) (North China pharmaceutical Co., Ltd., Shijiazhuang, China), Ceftazidime (CAZ) (Jida pharmaceutical Co., Ltd., Kunming, China), Azithromycin (AZM) and Levofloxacin (LEV) (Yangzhijiang pharmaceutical Co., Ltd., Taizhou, China). Vancomycin (Eli Lilly Japan K. K., Seishin Laboratories) was used as the positive control agent. Standard Cefoxitin disks were purchased from Tiantan biological products Co., Ltd. (Beijing, China).

\subsection{Bioassay-Guided Isolation and Identification of ISJ}

Powdered aerial parts of $H$. japonicum $(4.7 \mathrm{~kg}$ ) were extracted with $80 \%$ ethanol and the extract $(500 \mathrm{~g})$ was successively fractionated between water and petroleum ether $(\mathrm{P})$, ethyl acetate (E) and $n$-butanol to afford four fractions. The E fraction $(90 \mathrm{~g})$, which showed the most activity by the agar diffusion test described in Section 3.5 below (Table 1) [4], was subjected to column chromatography over silica gel (300-400 mesh; Qingdao, China) and eluted (200 mL/fraction) with ethyl acetate. TLC monitored the eluates and combined to afford three sub-fractions (Frs. A- $\mathrm{C}_{1-6}$ ), gradient elution of Fr. $\mathrm{C}_{2}$ with P-E-M (methanol) $(4: 1: 0.2-1: 1: 0.5)$ to furnish $20 \mathrm{mg}$ of pure ISJ: light-yellow powder; $\mathrm{C}_{18} \mathrm{H}_{14} \mathrm{O}_{6}$, ESI-MS: $m / z 327\left([\mathrm{M}+1]^{+}\right) ;{ }^{1} \mathrm{H}$ NMR $(400 \mathrm{MHz}) \delta: 7.58(1 \mathrm{H}, \mathrm{d}, J=8.8 \mathrm{~Hz}, \mathrm{H}-8), 7.05(1 \mathrm{H}, \mathrm{d}$, $\left.J=10.0 \mathrm{~Hz}, \mathrm{H}-4^{\prime}\right), 6.92(1 \mathrm{H}, \mathrm{d}, \mathrm{J}=8.8 \mathrm{~Hz}, \mathrm{H}-7), 6.15(1 \mathrm{H}, \mathrm{s}, \mathrm{H}-2), 5.72\left(1 \mathrm{H}, \mathrm{d}, J=10.0 \mathrm{~Hz}, \mathrm{H}-3^{\prime}\right)$, $1.44\left(6 \mathrm{H}, \mathrm{s}, 2^{\prime}, 2 \mathrm{Me}\right) ;{ }^{13} \mathrm{C}$ NMR (100 MHz) $\delta: 162.8$ (C-1), 98.8 (C-2), 160.2 (C-3), 102.7 (C-4), 51.7 (C-4a), 146.5 (C-4b), 132.9 (C-5), 152.9 (C-6), 115.4 (C-7), 116.6 (C-8), 113.3 (C-8a), 180.4 (C-9), 101.4 (C-9a), $78.6\left(\mathrm{C}-2^{\prime}\right), 127.8\left(\mathrm{C}^{\prime} 3^{\prime}\right), 113.8\left(\mathrm{C}-4^{\prime}\right), 28.3\left(\mathrm{C}-2^{\prime}-\mathrm{Me}\right)$. All the spectral data were identical with the literature [11]. 


\subsection{Susceptibility Testing}

The inhibition zone diameters (IZDs, $\mathrm{mm}$ ) of the extracts $(30 \mathrm{mg} / \mathrm{mL}$ in dimethyl sulfoxide) were determined by the agar diffusion method on MHA plates with inoculums of $1.5 \times 10^{8} \mathrm{CFU} / \mathrm{mL}$ of the microorganisms following the previous report [5]. MICs/MBCs were determined by standardized broth microdilution techniques with the final inoculums of $5 \times 10^{5} \mathrm{CFU} / \mathrm{mL}$ in each well of the 96-well plate according to the CLSI guidelines and incubated at $35{ }^{\circ} \mathrm{C}$ for $24 \mathrm{~h}[23,24]$. All the experiments were performed in duplicate, with concentrations ranging up to $1024 \mathrm{mg} / \mathrm{L}$ for AZM.

\subsection{Synergy Testing}

Potential anti-MRSA synergy was measured by FICIs from the chequerboard method and by time-kill curves as previous report [13]. The FIC of the combination was calculated by dividing the MIC of the ISJ-antibacterial agent combination by the MIC of ISJ or of the antibacterial agent used alone. The FICI was obtained by adding the FIC of the ISJ and that of the antibacterial agent. The FICI results were interpreted as follows: FICI $\leq 0.5$, synergy; $0.5<$ FICI $\leq 1$, additivity; and $1<$ FICI $<2$, indifference (or no effect) and FICI $\geq 2$, antagonism [13,25]. In the killing curves, synergy was defined as $\geq 2 \log _{10} \mathrm{CFU} / \mathrm{mL}$ increase in killing at $24 \mathrm{~h}$ with the combination, in comparison with the killing by the most active single drug. Additivity was defined as a $1-2 \log _{10} \mathrm{CFU} / \mathrm{mL}$ increase in kill with the combination in comparison with the most active single agent. Indifference was defined as $\pm 1 \log _{10} \mathrm{CFU} / \mathrm{mL}$ killing or growth. Combinations that resulted in $>1 \log _{10} \mathrm{CFU} / \mathrm{mL}$ bacterial growth in comparison with the least active single agent were considered to represent antagonism [15,26]. All experiments were performed in triplicate.

\section{Conclusions}

The in vitro anti-MRSA activities of Isojacareubin (ISJ) alone and its synergistic effects when used in combination with antibacterial agents demonstrated that ISJ may have potential clinical usage to enhance the efficacy of current antibacterials such as Ceftazidime and Levofloxacin, which warrants further pharmacological studies.

\section{Acknowledgments}

This work was supported by the National Natural Science Foundation of China (NSFC 81073126) and the supporting funds of Yunnan Provincial Science and Technology Department (2008PY001) and Medical Research Programme of Chengdu Military Region (MB09030) of China. We are also grateful to Kunming Institute of Botany (CAS) for spectral analysis.

\section{Conflict of Interest}

The authors declare no conflict of interest. 


\section{References}

1. Chang, S.; Sievert, D.M.; Hageman, J.C.; Boulton, M.L.; Tenover, F.C.; Downes, F.P.; Shah, S.; Rudrik, J.T.; Pupp, G.R.; Brown, W.J.; et al. Infection with vancomycin-resistant Staphylococcus aureus containing the vanA resistance gene. N. Engl. J. Med. 2003, 348, 1342-1347.

2. Wagner, H.; Ulrich-Merzenich, G. Synergy research: Approaching a new generation of phytopharmaceuticals. Phytomedicine 2009, 16, 97-110.

3. Hemaiswarya, S.; Kruthiventi, A.K.; Doble, M. Synergism between natural products and antibiotics against infectious diseases. Phytomedicine 2008, 15, 639-652.

4. Zuo, G.Y.; Wang, G.C.; Zhao, Y.B.; Xu, G.L.; Hao, X.Y.; Han, J.; Zhao, Q. Screening of Chinese medicinal plants for inhibition against clinical isolates of methicillin-resistant Staphylococcus aureus (MRSA). J. Ethnopharmacol. 2008, 120, 287-290.

5. Zuo, G.Y.; Zhang, X.J.; Yang, C.X.; Han, J.; Wang, G.C.; Bian, Z.Q. Evaluation of traditional Chinese medicinal plants for anti-MRSA activity with reference to the treatment record of infectious diseases. Molecules 2012, 17, 2955-2967.

6. Zuo, G.Y.; Meng, F.Y.; Hao, X.Y.; Zhang, Y.L.; Wang, G.C.; Xu, G.L. Antibacterial Alkaloids from Chelidonium majus Linn (Papaveraceae) against clinical isolates of methicillin-resistant Staphylococcus aureus. J. Pharm. Pharm. Sci. 2008, 11, 90-94.

7. Zuo, G.Y.; Li, Y.; Wang, T.; Han, J.; Wang, G.C.; Zhang, Y.L.; Pan, W.D. Synergistic antibacterial and antibiotic effects of bisbenzylisoquinoline alkaloids on clinical isolates of methicillin-resistant Staphylococcus aureus (MRSA). Molecules 2011, 16, 9819-9826.

8. An, J.; Zuo, G.Y.; Hao, X.Y.; Wang, G.C.; Li, Z.S. Antibacterial and synergy of a flavanonol rhamnoside with antibiotics against clinical isolates of methicillin-resistant Staphylococcus aureus (MRSA). Phytomedicine 2011, 18, 990-993.

9. Tian-ji-huang. In Selected Yunnan Traditional Chinese Herbs; Tianjin People's Press: Tianjin, China, 1970; Volume I, pp. 30-31.

10. Di-er-cao. In Dictionary of Chinese Materia Medica; Shanghai Scientific Technical Press: Shanghai, China, 1977; Volume I, pp. 813-814.

11. Ishiguro, K.; Nagata, S.; Fukumoto, H.; Yamaki, M.; Isoi, K.; Oyama, Y. An isopentenylated flavonol from Hypericum japonicum. Phytochemistry 1993, 32, 1583-1585.

12. Zhang, K.; McClure, J.A.; Elsayed, S.; Louie, T.; Conly, J.M. Novel multiplex PCR assay for characterization and concomitant subtyping of staphylococcal cassette chromosome mec types I to V in methicillin-resistant Staphylococcus aureus. J. Clin. Microbiol. 2005, 43, 5026-5033.

13. Hu, Z.Q.; Zhao, W.H.; Asano, N.; Yoda, Y.; Hara, Y.; Shimamura, T. Epigallocatechin gallate synergistically enhances the activity of carbapenems against methicillin resistant Staphylococcus aureus. Antimicrob. Agents. Chemother. 2002, 46, 558-560.

14. Clinical and Laboratory Standards Institute (CLSI). Performance Standards for Antimicrobial Susceptibility Testing-17th Informational Supplement; Approved Standard M100-S17; CLSI: Wayne, PA, USA, 2007. 
15. Petersen, P.J.; Labthavikul, P.; Jones, C.H.; Bradford, P.A. In vitro antibacterial activities of tigecycline in combination with other antimicrobial agents determined by chequerboard and time-kill kinetic analysis. J. Antimicrob. Chemother. 2006, 57, 573-576.

16. National Pharmacopoeia Committee of China. Tianjihuang zhusheye (Injectio Hyperici Japonici). In Pharmacopoeia of the People's Republic of China (Part 1); Chemical Industry Press: Beijing, China, 1977; pp. 199-200.

17. Di Carlo, G.; Borrelli, F.; Izzo, A.A.; Ernst, E. St John's wort: Prozac from the plant kingdom. Trends Pharmacol. Set. 2001, 22, 292-297.

18. Chomnawang, M.T.; Surassmo, S.; Wongsariya, K.; Bunyapraphatsara, N. Antibacterial activity of Thai medicinal plants against methicillin-resistant Staphylococcus aureus. Fitoterapia 2009, 80, 102-104.

19. Sukpondma, Y.; Rukachaisirikul, V.; Phongpaichit, S. Antibacterial caged-tetraprenylated xanthones from the fruits of Garcinia hanburyi. Chem. Pharm. Bull. 2005, 53, 850-852.

20. Yasunaka, K.; Abe, F.; Nagayama, A.; Okabe, H.; Lozada-Perez, L.; Lopez-Villafranco, E.; Muniz, E.E.; Aguilar, A.; Reyes-Chilpa, R. Antibacterial activity of crude extracts from Mexican medicinal plants and purified coumarins and xanthones. J. Ethnopharmacol. 2005, 97, 293-299.

21. Clinical and Laboratory Standards Institute (CLSI). Performance Standards for Antimicrobial Disk Susceptibility Tests; Approved standard M02-A10; CLSI: Wayne, PA, USA, 2006.

22. Kloos, W.K.; Bannerman, T.L. Staphylococcus and Micrococcus. In Manual of Clinical Microbiology, 7th ed.; Murray, P.R., Baron, E.J., Pfaller, M.A., Tenover, F.C., Yolken, R.H., Eds.; ASM Press: Washington, DC, USA, 1999; pp. 264-282.

23. Clinical and Laboratory Standards Institute (CLSI). Methods for Dilution Antimicrobial Susceptibility Tests for Bacteria that Grow Aerobically, 7th ed.; Approved standard M7-A7; CLSI: Wayne, PA, USA, 2006.

24. Clinical Laboratory Standards Institute (CLSI). Methods for Determining Bactericidal Activity of Antimicrobial Agents; Document M26-A; CLSI: Wayne, PA, USA, 1999.

25. Orhan, G.; Bayram, A.; Zer, Y.; Balci, I. Synergy tests by $E$ test and chequerboard methods of antimicrobial combinations against Brucella melitensis. J. Clin. Microbiol. 2005, 43, 140-143.

26. Chin, J.N.; Jones, R.N.; Sader, H.S.; Savage, P.B.; Rybak, M.J. Potential synergy activity of the novel ceragenin, CAS-13, against clinical isolates of Pseudomonas aeruginosa, including multidrug-resistant P. aeruginosa. J. Antimicrob. Chemother. 2008, 61, 365-370.

(C) 2012 by the authors; licensee MDPI, Basel, Switzerland. This article is an open access article distributed under the terms and conditions of the Creative Commons Attribution license (http://creativecommons.org/licenses/by/3.0/). 